
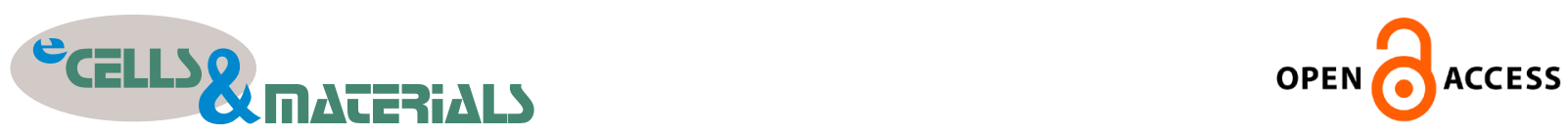

\title{
TRANSCRIPTIONAL ACTIVATION OF ENPP1 BY OSTERIX IN OSTEOBLASTS AND OSTEOCYTES
}

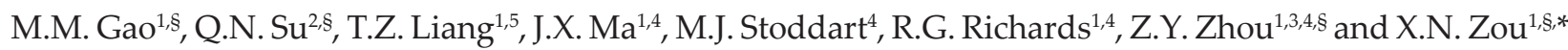 \\ ${ }^{1}$ Guangdong Provincial Key Laboratory of Orthopaedics and Traumatology/Orthopaedic Research Institute, \\ The First Affiliated Hospital of Sun Yat-sen University, Guangzhou, China \\ ${ }^{2}$ School of Medicine, Shenzhen University, Shenzhen, China \\ ${ }^{3}$ Department of Orthopaedic Surgery, The Seventh Affiliated Hospital of Sun Yat-sen University, \\ Shenzhen, China \\ ${ }^{4}$ AO Research Institute Davos, Davos, Switzerland \\ ${ }^{5}$ Department of Orthopaedic Surgery, The Third Affiliated Hospital of Sun Yat-sen University, \\ Guangzhou, China \\ $\S$ These authors contributed equally
}

\begin{abstract}
Ectonucleotide pyrophosphatase/phosphodiesterase 1 (ENPP1) is the main source of extracellular pyrophosphate. Along with tissue-nonspecific alkaline phosphatase (TNAP), ENPP1 plays an important role in balancing bone mineralisation. Although well established in pre-osteoblasts, the regulating mechanisms of ENPP1 in osteoblasts and osteocytes remain largely unknown. Using bioinformatic methods, Osterix (Osx), an essential transcription factor in osteoblast differentiation and osteocyte function, was found to have five predicted binding sites on the ENPP1 promoter. ENPP1 and Osx showed a similar expression profile both in vitro and in vivo. Over-expression of Osx in MC3T3-E1 and MLO-Y4 cells significantly up-regulated the expression of ENPP1 $(p<0.05)$. The consensus Sp1 sequences, located in the proximal ENPP1 promoter, were identified as Osx-regulating sites using promoter truncation experiments and chromatin immunoprecipitation (ChIP) assays. The p38-mitogen-activated protein kinase (MAPK) signalling pathway was demonstrated to be responsible for ENPP1 promoter activation by Osx. Runt-related transcription factor 2 (Runx2) was confirmed to have synergistic effects with Osx in activating ENPP1 promoter. Taken together, these results provided evidence of the regulating mechanisms of ENPP1 transcription in osteoblasts and osteocytes.
\end{abstract}

Keywords: Pyrophosphatase/phosphodiesterase 1, Osterix, gene regulation, mineralisation, osteogenesis.

*Address for correspondence: Professor Xuenong Zou, Guangdong Provincial Key Laboratory of Orthopaedics and Traumatology/Orthopaedic Research Institute, The First Affiliated Hospital of Sun Yat-sen University, Guangzhou, Guangdong, China.

Telephone: + 8620877557668010 ......Email: zxnong@hotmail.com

Copyright policy: This article is distributed in accordance with Creative Commons Attribution Licence (http://creativecommons.org/licenses/by-sa/4.0/).

\section{Introduction}

Ectonucleotide pyrophosphatase/phosphodiesterase 1 (ENPP1) is a type II transmembrane glycoprotein comprising two identical disulphide-bonded subunits. It is expressed in pre-osteoblasts (Nam et al., 2011), osteoblasts and osteocytes (Kato et al., 2012). ENPP1 has a broad specificity and cleaves a variety of substrates, including nucleotide sugars, phosphodiester and pyrophosphate bonds (Evans et al., 1973). Coordinating with tissue-nonspecific alkaline phosphatase (TNAP), ENPP1 generates pyrophosphate (PPi) from extracellular nucleotides (Stefan et al., 2005). As an inhibitor of hydroxyapatite crystal formation, PPi is further hydrolysed by TNAP, releasing phosphate $(\mathrm{Pi})$ and changing the $\mathrm{Pi} / \mathrm{PPi}$ ratio, which is crucial for bone mineralisation (Hessle et al., 2002; Moss et al., 1967). The function of ENPP1 in mineralisation is firstly stated in the tiptoe walking $(t t w / t t w)$ mice, which are characterised by ectopic ossification and altered bone development (Okawa et al., 1998; Rutsch et al., 2003; Sakamoto et al., 1994). Moreover, in a mouse model lacking ENPP1 $\left(\right.$ Enpp $\left.^{-/-}\right)$, Mackenzie et al. (2012) observe that the 
architecture and mineralisation of long-bones are severely disrupted. These results indicate the critical role of ENPP1 in regulating bone mineralisation homeostasis.

Knowledge of the upstream mechanisms that regulate ENPP1 is essential for a better understanding of the physical process of bone mineralisation. Distalless homeobox (DLX3) inhibits ENPP1 expression during bone development (Isaac et al., 2014). Fibroblast growth factor 2 (FGF2) can induce ENPP1 expression in pre-osteoblasts only by the mediation of osteoblast-related transcription factors, such as Msh homeobox 2 (Msx2) (Li et al., 2010) and runt-related transcription factor 2 (Runx2) (Hatch et al., 2009). The regulating mechanisms in osteoblasts and osteocytes are still unknown.

Osterix (Osx), a zinc-finger-containing transcription factor, is present in all developing stages of bone and is essential for osteogenic differentiation, osteocyte maturation and function and bone mineralisation homeostasis (Nakashima et al., 2002; Zhou et al., 2010). On one hand, Osx activates the transcription of collagen type I alpha 1 chain (Col1a1) (Nakashima et al., 2002; Zhou et al., 2010), osteocalcin (Niger et al., 2011) and special AT-rich sequencebinding protein 2 (SATB2) (Conner and Hornick, 2013) to promote primary crystal formation and hydroxyapatite deposition. On the other hand, Osx inhibits late stage osteogenic differentiation (Yoshida et al., 2012) and activates osteopontin and sclerostin expression (Perez-Campo et al., 2016; Poole et al., 2005) to restrain bone mineralisation. These results reveal the regulatory role of Osx in bone mineralisation homeostasis by acting on a series of mineralisationrelated genes in osteoblasts and osteocytes. However, there are still no studies on Osx regulation of ENPP1 expression.

Based on these findings, the working hypothesis was that Osx could transcriptionally regulate ENPP1 in osteoblasts and osteocytes. This study showed that Osx and ENPP1 exhibited similar expression profiles both in vitro and in vivo and that over-expression of Osx could dramatically induce ENPP1 expression. Using promoter truncation and chromatin immunoprecipitation (ChIP) assays, the binding regions of Osx on the ENPP1 promoter was identified in different conditions. The p38-mitogenactivated protein kinase (MAPK) signalling pathway was shown to be involved in the process and the synergistic effects of Osx and Runx2 on the upregulation of ENPP1 expression was demonstrated.

\section{Materials and Methods}

\section{Cell culture and osteoblastic induction}

MC3T3-E1 subclone 14 cell line was purchased from ATCC. MLO-Y4 cell line was purchased from JENNIO Biological Technology (Guangzhou, China). MC3T3-E1 cells were maintained in alpha modification Eagle's medium ( $\alpha$-MEM) (Gibco) supplemented with $10 \%$ foetal bovine serum (FBS) (Gibco), $100 \mathrm{U} / \mathrm{mL}$ penicillin (Gibco) and $100 \mu \mathrm{g} / \mathrm{mL}$ streptomycin (Gibco). MLO-Y4 cells were cultured on type-I-collagen-coated plates in $\alpha$-MEM with $5 \%$ FBS, $5 \%$ foetal calf serum (Hyclone), $100 \mathrm{U} /$ $\mathrm{mL}$ penicillin and $100 \mu \mathrm{g} / \mathrm{mL}$ streptomycin. Human bone-marrow-derived mesenchymal stem/stromal cells (hBMSCs) were isolated from three patients (one male, two females) with lumbar degenerative diseases. Briefly, bone marrow was collected from the drilled holes of the pedicle during internal fixation of the spine (Tang et al., 2011). Informed consents for bone marrow collection were obtained from the patients. All procedures were performed in accordance with the guidance and approval of the research ethics committee of the First Affiliated Hospital of Sun Yat-sen University, Guangzhou, Guangdong, China (No. 2008-55). Mononuclear cells were purified from the bone marrow by density gradient centrifugation using Ficoll-Paque ${ }^{\mathrm{TM}}$ PREMIUM (1.077; GE Healthcare) according to the manufacturer's instructions. The isolated cells were cultured in Dulbecco's modified Eagle medium (DMEM) with $4.5 \mathrm{~g} / \mathrm{L}$ glucose (Gibco) and $10 \%$ FBS. The medium was changed every $3 \mathrm{~d}$. Passage 3 cells were used in the study.

To induce osteoblastic differentiation, cells were incubated in osteogenic medium (OM) or basic medium (control). The OM contained $10 \mathrm{mM} \beta$-glycerophosphate (Sigma-Aldrich), $50 \mu \mathrm{g} / \mathrm{mL}$ ascorbic acid (Sigma-Aldrich) and $1 \mu \mathrm{M}$ dexamethasone (Sigma-Aldrich). The medium was changed every $3 \mathrm{~d}$. Cells were collected at day 7, 14 and 21 after induction for further evaluation. All the experiments were independently repeated 3 times, with 3 repetitions for each condition.

\section{Plasmids and cell transfection}

Murine Osx, Runx2, mitogen-activated protein kinase kinase 6 (MKK6) and activated MKK6EE expression constructs were generated by PCR and sub-cloned into pcDNA3.1-hisC basic vector (Invitrogen). Mouse ENPP1 promoter reporter constructs from nucleotide -2585 to +230 (2585-pENPP1) were generated by PCR and sub-cloned into PGL-3 basic vector (Promega). 1347-pENPP1, 1031-pENPP1, 829-pENPP1, 349-pENPP1 and 280-pENPP1 were generated by restriction enzyme digestion of 2585-pENPP1. PRL-TK vector (Promega) was used as control in dual luciferase assays. The primers used for vector construction are listed in Table 1. Lipofectamine ${ }^{\mathrm{TM}} 2000$ Transfection Reagent (Invitrogen) was used in the transient transfection. MC3T3-E1 cells were transfected in the undifferentiated status and MLO-Y4 cells were transfected at a confluence of $70-80 \%$. All cells were transfected for $4 \mathrm{~h}$ and cultivated in $\alpha$-MEM with $10 \%$ FBS for another $24 \mathrm{~h}$. Recombinant human/murine/ rat BMP-2 (Escherichia-coli-derived) was purchased 

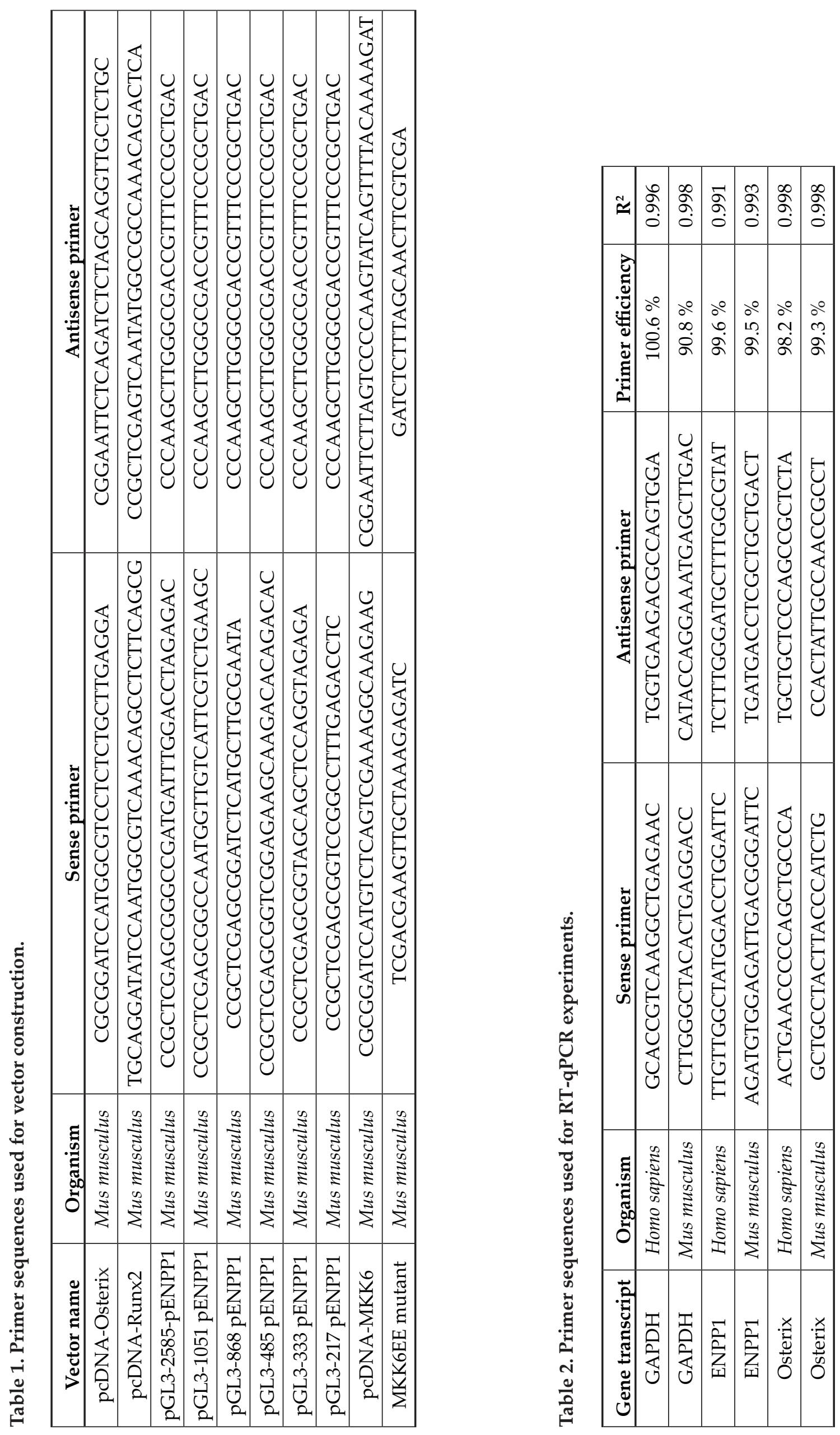
Table 3. Primer sequences used for ChIP assays.

\begin{tabular}{|c|c|c|}
\hline Gene transcript & Sense primer & Antisense primer \\
\hline ChIP site 1 & TTCTCCTGCTGTCACTCATTGG & GGCTAGAGTAGGATTAAACCGTAGA \\
\hline ChIP site 2 & TGAAAGTGGAAGTCAGAACTACC & CCAGCCAGCCTAGCCTATT \\
\hline ChIP site 3 & TCATGCTTGCGAATACCAGAACT & TAACGGGTGTAAATTGGGTTTGTC \\
\hline ChIP site 4 & CGGACGCCACACATCCCATA & TTCTCCCACAAGTGCAAACGAAA \\
\hline ChIP site 5 & TTAGCAGCTCCAGGTAGAGAATT & TGACCAGGGAAATGCAAACGA \\
\hline
\end{tabular}

from PeproTech Inc. and used at a final concentration of $2 \mathrm{nM}$ to induce p38-MAPK pathway activation, while SB203580 (Calbiochem) was applied at a final concentration of $10 \mu \mathrm{M}$ to inhibit p38-MAPK pathway activation.

\section{Real-time reverse transcription PCR (RT-qPCR)} Total RNA was extracted using TRIzol (Invitrogen) reagent according to the manufacturer's protocol. Reverse transcription was performed using SuperScript ${ }^{\circledast}$ VILO $^{\text {TM }}{ }^{2 D N A}$ Synthesis Kit (Invitrogen) according to the manufacturer's instruction. The CXF-96 detection system (Bio-Rad Laboratories) was used to conduct RT-qPCR. Gene expression of ENPP1 (Homo sapiens/Mus musculus), glyceraldehyde 3-phosphate dehydrogenase (GAPDH, Homo sapiens) Mus musculus) and Osx (Homo sapiens/Mus musculus) was analysed using custom-designed primers (Table 2). Amplification was conducted for all genes using SYBR Green Master Mix (Applied Biosystems). The experiments were independently repeated 3 times, with 3 repetitions for each group and technical triplicates. CT values were averaged from triplicate samples. Then, values of individual gene were normalised to the value of the housekeeping gene GAPDH.

\section{Western blot analysis}

Western blot analysis was performed using standardised methods. Undifferentiated MC3T3-E1 cells at a confluence of 70-80 \% were transfected with Osx over-expression construct or basic vector for $4 \mathrm{~h}$ and cultivated in $\alpha$-MEM with $10 \%$ FBS for another $24 \mathrm{~h}$. 25-50 $\mu \mathrm{g}$ of protein extracted from cells were separated by sodium dodecyl sulphate polyacrylamide gel electrophoresis and transferred onto nitrocellulose membranes. Then, membranes were blocked, immunoblotted overnight at $4{ }^{\circ} \mathrm{C}$ with relevant primary antibodies and probed $1 \mathrm{~h}$ at room temperature with the appropriate secondary peroxidase-conjugated antibodies. The immunoblots were visualised by enhanced chemiluminescence. Goat polyclonal antibody against ENPP1 (ab40003; Abcam) was used at a concentration of $3 \mu \mathrm{g} / \mathrm{mL}$. Mouse monoclonal antibody against GAPDH (ab8245; Abcam), goat anti-mouse HRP (ab6789; Abcam) and donkey anti-goat HRP (ab6885; Abcam) were used at $1: 10,000$ dilution. The experiment was repeated 3 times.
Animal study and immunofluorescence staining 6 d postnatal C57Bl6/j mice (Medical Laboratory Animal Centre, Guangdong, China) were euthanised and the tibiae were separated after perfusion with normal saline and $4 \%$ paraformaldehyde. After $6 \mathrm{~h}$ of tissue fixation in $4 \%$ paraformaldehyde at $4{ }^{\circ} \mathrm{C}$, specimens were washed for 3 times in phosphate buffered saline (PBS) and decalcified for $24 \mathrm{~h}$ at $4{ }^{\circ} \mathrm{C}$ in $10 \%$ ethylenediaminetetraacetic acid (EDTA). After washing 3 times with PBS, specimens were infiltrated overnight in $20 \%$ sucrose solution for dehydration. All specimens were embedded in optimal cutting temperature (OCT) compound and cut into $10 \mu \mathrm{m}-$ thick cryosections for further immunofluorescence staining. Single plane images were acquired using Zeiss LSM-710 confocal microscope. Each experiment was repeated 3 times. Goat polyclonal antibody against ENPP1 and rabbit polyclonal antibody against Osx (ab22552; Abcam) were used at $1: 100$ dilution. Donkey anti-goat IgG (H + L) (705-605003; Alexa Fluor ${ }^{\circledR}$ 647) and donkey anti-rabbit IgG $(\mathrm{H}+\mathrm{L})$ (711-545-152; Alexa Fluor ${ }^{\circledR} 488$ ) (Jackson ImmunoResearch Inc.) were used at $1: 250$ dilution.

\section{Dual-luciferase reporter assay}

MC3T3-E1 cells at 90\% confluence were transfected for $4 \mathrm{~h}$ and cultivated in $\alpha$-MEM with $10 \%$ FBS for another $24 \mathrm{~h}$. Then, the dual-luciferase reporter assays were performed using DLR ${ }^{\mathrm{TM}}$ Assay System (Promega), according to the manufacturer's instructions. PGL-3-reporter vector and PRL-TK vector were transfected at a ratio of $20: 1$. Results were considered to be valid only if the Renilla luciferase luminescent reaction was not 1,000-fold lower than the intensity of the firefly luciferase. Luminescence was detected using a Mithras LB 940 (Berthold Technologies, Oak Ridge, TN, USA). The relative luciferase activity was calculated as the ratio of firefly luciferase activity of the reporter gene plasmid/Renilla luciferase activity (internal control) of pRL-TK vector. Each assay was repeated 3 times, with technical triplicates performed.

\section{ChIP}

$1 \mathrm{~d}$ postnatal C57B16/j mice were sacrificed and the posterior limbs were separated after perfusion with normal saline and cut into small pieces $\left(1-3 \mathrm{~mm}^{3}\right)$. MLO-Y4 cells were cultured in $100 \mathrm{~mm}$ dishes and used for experiments at a final confluence of 70-80 \%. 
All samples were incubated in $1 \%$ formaldehyde solution for $15 \mathrm{~min}$ and the reaction was stopped by adding glycine solution at a final concentration of $0.125 \mathrm{M}$. After washing in PBS, the Medimachine (Becton, Dickinson and Company) was used to obtain a single cell suspension. Then, ChIP assays were performed using the ChIP Assay Kit (Beyotime, Shanghai, China) according to the manufacturer's instructions. Each experiment was repeated 3 times. Rabbit polyclonal antibody against Osx (Abcam) was used at the concentration of $5 \mathrm{mg} / \mathrm{mL}$ and rabbit $\mathrm{IgG}$
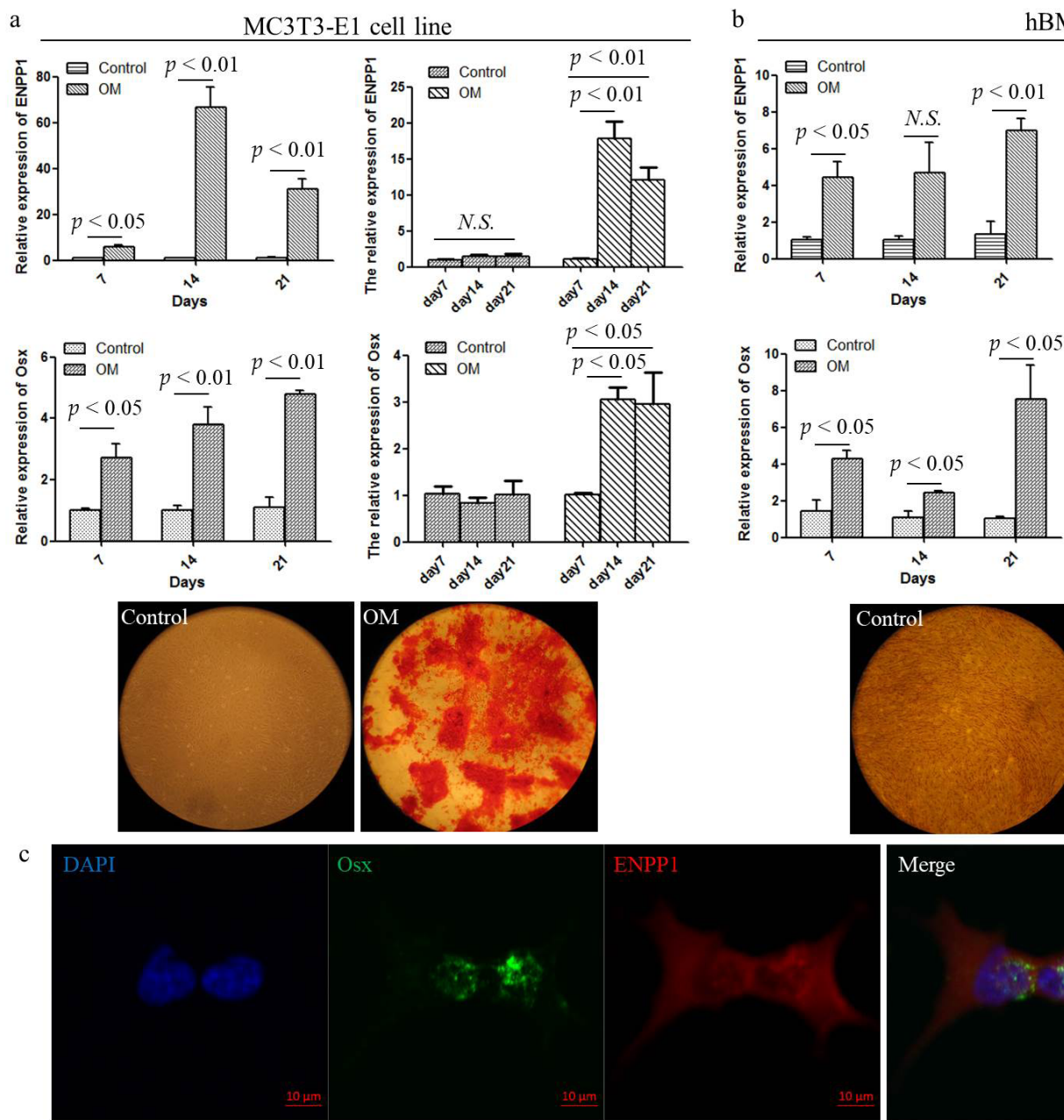

hBMSCs
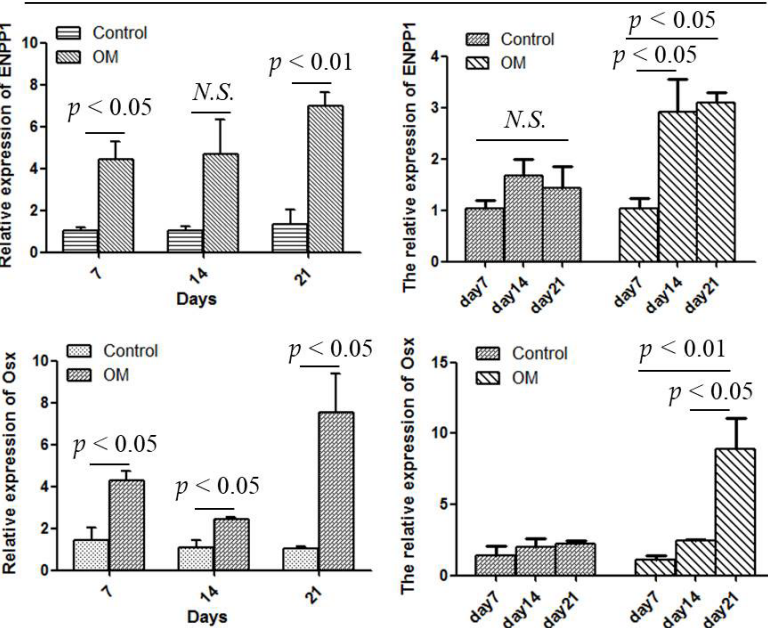

Statistical analysis

Statistical analysis was performed using SPSS 16.0 statistical software. Student's $t$-test and oneway ANOVA followed by Bonferroni's multiple comparison tests were utilised. Quantitative data are presented as means \pm standard error of the mean (SEM). $p<0.05$ was considered statistically significant.

d

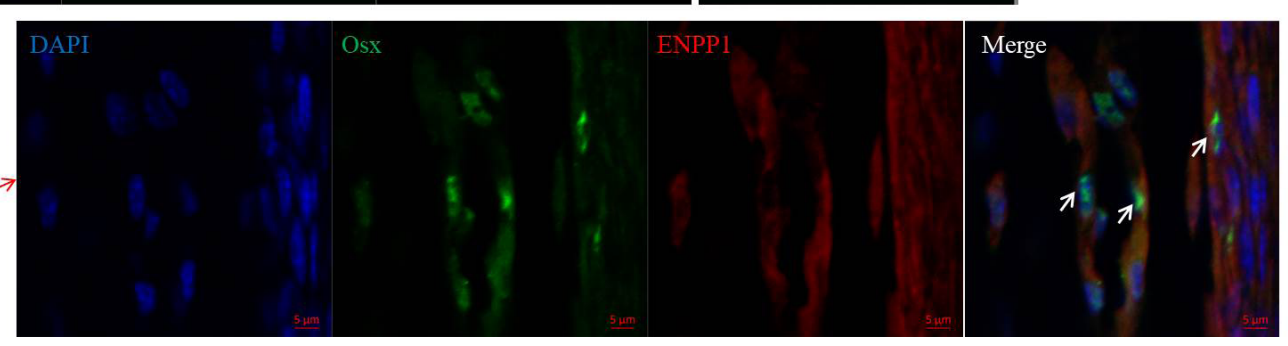

Fig. 1. Expression profile of ENPP1 and Osx in vitro and in vivo. (a) MC3T3-E1 cells and (b) hBMSCs were cultivated in OM or basic medium (control) for 7, 14 and $21 \mathrm{~d}$. The experiments were independently repeated 3 times with 3 repetitions for each condition. The mRNA expression levels of ENPP1 and Osx at each time point were detected by RT-qPCR, with technical triplicates performed. Comparison between two groups or expression change with cultivation time were analysed. Alizarin red staining was performed at $21 \mathrm{~d}$. (c) The immunofluorescent co-staining results showed the expression pattern of Osx and ENPP1 in MLO-Y4 cells. ENPP1 (green); Osx (red); nuclei, 4',6-diamidino-2-phenylindole (DAPI, blue). (d) The immunofluorescent co-staining results showed the expression pattern of Osx and ENPP1 in the tibiae of $6 \mathrm{~d}$ postnatal mice. The red box on the left image surrounds part of the cortical bone and periosteum with Osx and ENPP1 co-expression (white arrows). 


\section{Results}

Expression profiles of ENPP1 and Osx were similar during osteogenesis in vitro and in vivo MC3T3-E1 cells and hBMSCs were cultivated in OM or basic medium (control) for 7, 14 and $21 \mathrm{~d}$. Both ENPP1 and Osx were significantly higher in OM than in control $(p<0.05)$. Moreover, ENPP1 and Os $x$ simultaneously increased expression during osteogenic cultivation $(p<0.05)$. Alizarin red staining at day 21 showed calcium nodus formation in the osteogenic groups (Fig. 1a,b). In MLO-Y4, the confocal images showed the co-expression of ENPP1 and Osx (Fig. 1c). To explore the distribution of ENPP1 and Osx in vivo, tibiae of $6 \mathrm{~d}$ postnatal mice were sectioned for immunofluorescence co-staining: ENPP1 and Osx co-expressed in cortical bone and periosteum (white arrows) (Fig. 1d).

Osx transfection up-regulated ENPP1 expression To investigate the regulation of Osx on ENPP1 expression, the Osx over-expression construct (OverOsx) or the control vector were transfected into undifferentiated MC3T3-E1 and MLO-Y4 cells for $4 \mathrm{~h}$ and cultivated in $\alpha$-MEM with $10 \%$ FBS for another $24 \mathrm{~h}$. RT-qPCR results showed that the mRNA expression of ENPP1 was significantly increased following the transfection $(p<0.05)$ (Fig. 2a,b). Protein levels of ENPP1 and Osx were significantly increased in MC3T3-E1 cells in the Over-Osx group $(p<0.01)$ (Fig. 2c,d).

\section{Activation of ENPP1 promoter by Osx}

To gain further insight into the mechanisms of ENPP1 expression regulation by Osx, a 3-kbp-long region comprising the promoter, $5^{\prime}$ untranslated region (UTR) and coding sequence of ENPP1 were obtained from the UCSC Genome Browser (Web ref. 1) and the sequence conservation was analysed using the UCSC BLAT Search (Web ref. 2). Results showed that the sequence was highly conserved between multiple vertebrate species (Fig. 3a). Transcription start sites were predicted using Promoter 2.0 Prediction Server (Web ref. 3), which showed a "highly likely prediction" site starting from position -301 (Fig. 3b). Based on the above analysis results and previous results relating to ENPP1 regulation, a 2.6-kbp-long promoter region and the entire $5^{\prime}$ UTR sequence were chosen for further study. JASPAR core database (Web ref. 4) was used for matches of Sp1 binding matrices. The relative scores of matrices similarity were set to 0.8. As shown in Fig. 3c, 5 predicted binding sites were reported. Luciferase reporter constructs with the 2.6-kbp-long murine promoter sequence of ENPP1 were constructed for dual-luciferase reporter assays. Results showed that Osx could significantly increase the luciferase activity in MC3T3-E1 cells transfected with 2585-pENPP1 construct when compared with

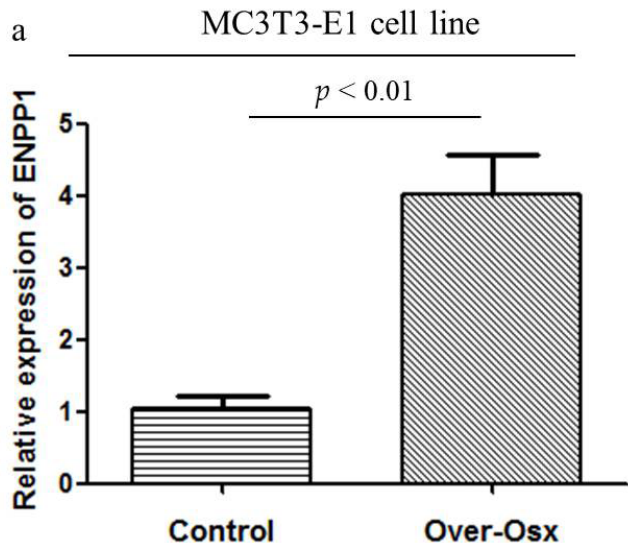

$\mathrm{b}$
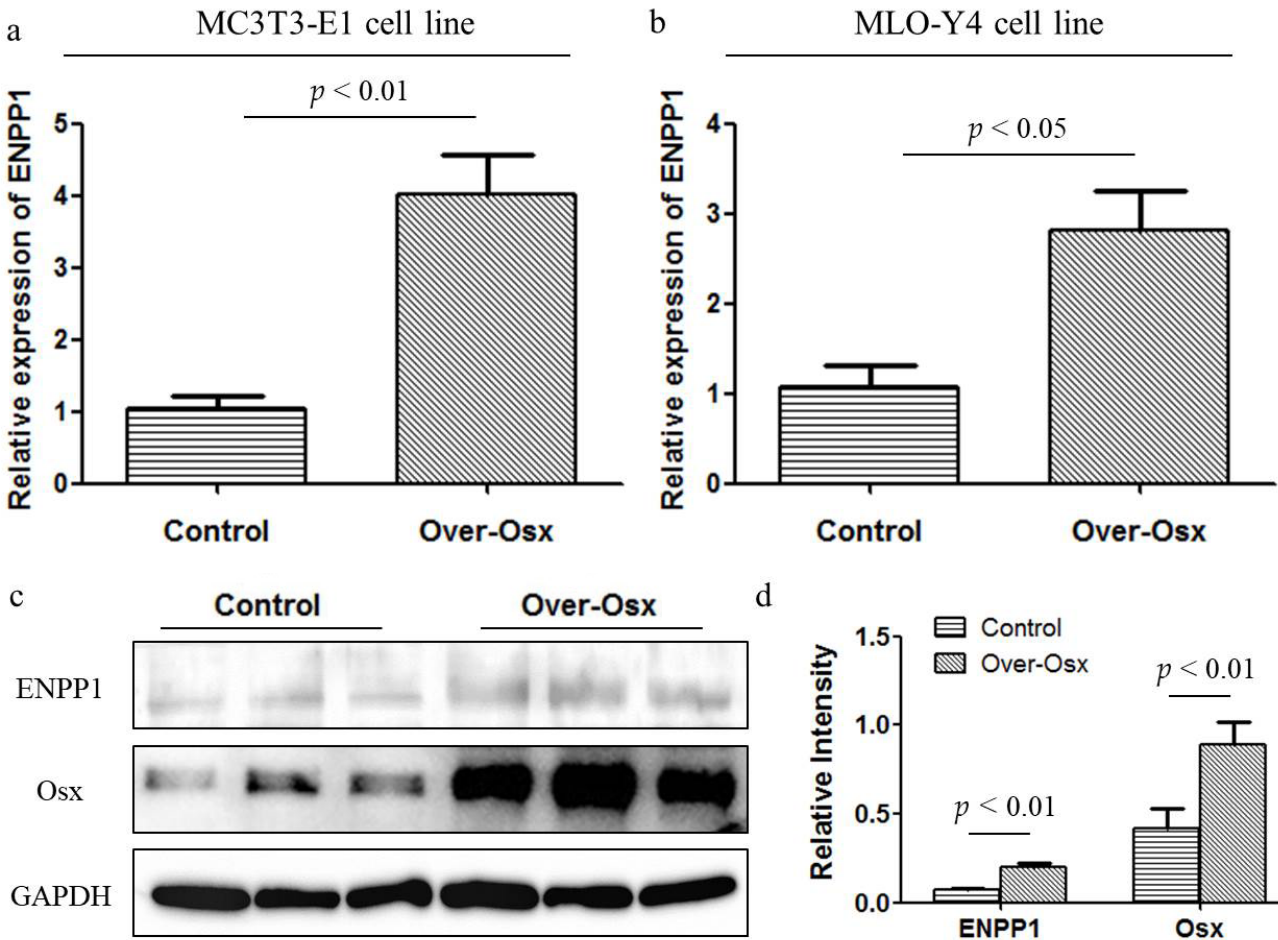

d

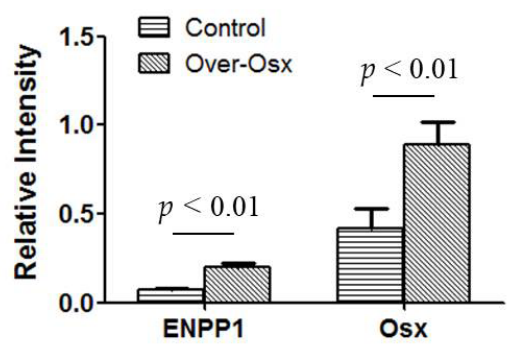

Fig. 2. Up-regulation of ENPP1 induced by Osx. (a) Undifferentiated MC3T3-E1 cells and (b) MLO-Y4 cells at a confluence of 70-80 \% were transfected with Osx over-expression construct (Over-Osx) or basic vector (Control) for $4 \mathrm{~h}$ and cultivated in $\alpha$-MEM with $10 \%$ FBS for another $24 \mathrm{~h}$. The relative mRNA expression of ENPP1 was detected by RT-qPCR. (c) Representative image of western blot results showing the protein levels of ENPP1 and Osx in MC3T3-E1 cells after transfection with Osx over-expression construct (OverOsx) or basic vector (Control). (d) Quantification of 3 repetitions of the western blot results. 
the control group transfected with PGL-3 basic vector $(p<0.01)$, thus demonstrating the direct activation of ENPP1 by Osx (Fig. 3d). To further define the binding sites, promoter truncation experiments were performed. Results showed that the luciferase activity of 1347-pENPP1, 1031-pENPP1, 829-pENPP1, 349-pENPP1 and 280-pENPP1 was significantly higher than the control group $(p<0.01)$ and the luciferase activity was decreased after truncation of site 2 (Fig. 3d). ChIP results showed that Osx could bind any of the 5 predicted sites with equal input of incidence in the tibiae of $6 \mathrm{~d}$ postnatal mice (Fig. 3e). In MLO-Y4 cells, Osx activated ENPP1 expression by binding any of the predicted site except for site 4 $(-349$ to -340$)$ (Fig. 3f).
p38-MAPK pathway contributed to Osx activation of ENPP1 promoter

Next, the question whether p38 kinase was involved in Osx regulation of ENPP1 activation in undifferentiated MC3T3-E1 was explored. Both the expression of $O s x$ (Fig. 4a) and ENPP1 (Fig. 4b) were significantly increased by $24 \mathrm{~h}$ treatment with bone morphogenic protein 2 (BMP-2), which was abolished by the p38 inhibitor SB203580 $(p<0.05)$. Similarly, treatment with SB203580 inhibited Osx (Fig. 4c) and ENPP1 (Fig. $4 d)$ expression in the Osx over-expressing condition $(p<0.05)$. To further confirm the relevance of p38 in the regulation, the constitutive active MKK6 mutant expressional construct (MKK6EE) was transfected into MC3T3-E1 cells for $4 \mathrm{~h}$ and cultivated in $\alpha$-MEM

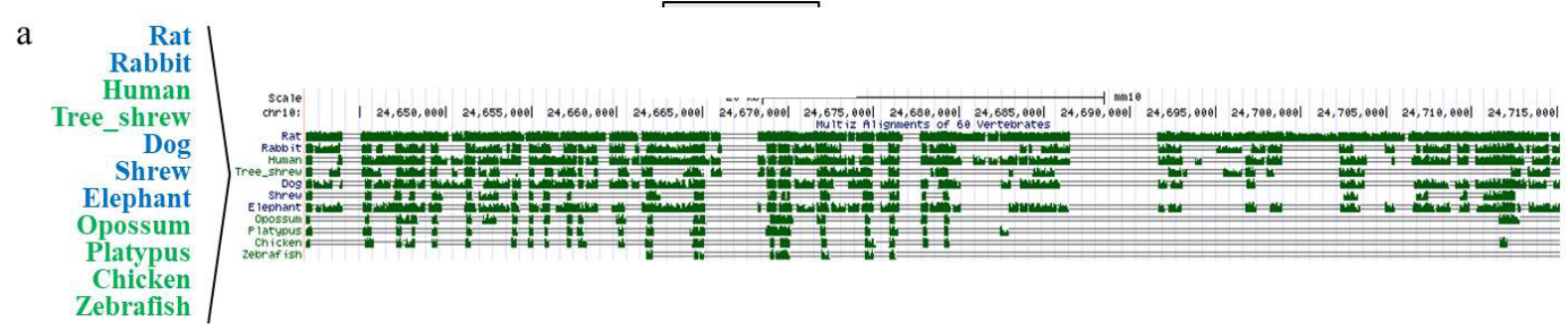

b PREDICTED TRAISCRIPTIOII START SITES:

mm10_knownGene_uc011xbs. 2 range_chr10_24711992-24715159 5_pad_0 3_pad_0 strand_- repeatMasking_none, 3168 nucleotides Position Score Likelihood

2700 1.259 Highly likely prediction
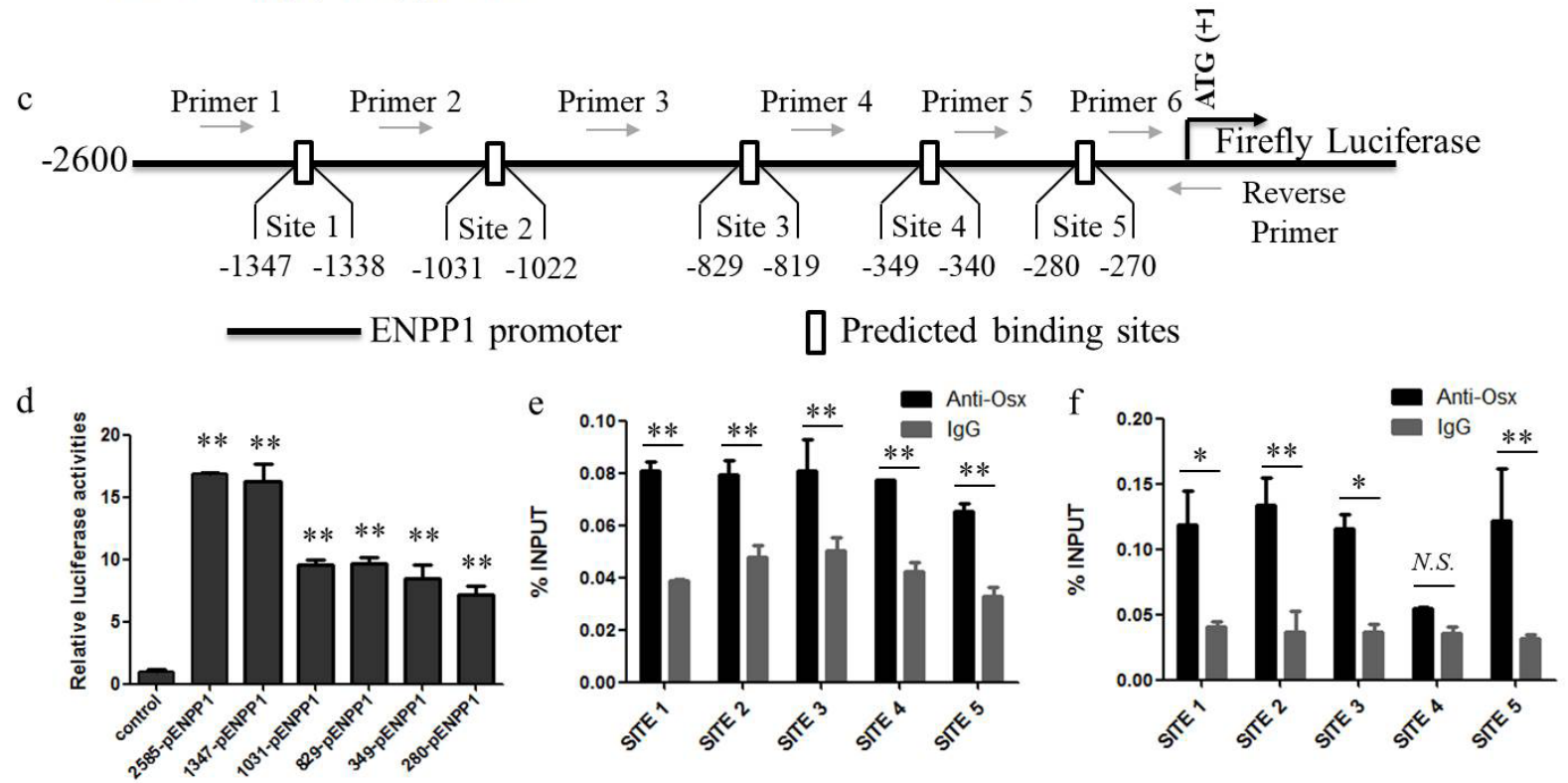

Fig. 3. Activation of ENPP1 promoter by Osx. (a) Analysis of conservation between multiple vertebrate species using the UCSC BLAT Search (Web ref. 2). (b) Prediction of ENPP1 transcription starting sites using the database of Promoter 2.0 Prediction Server (Web ref. 3). (c) Schematic diagram showing the luciferase construct with predicted binding sites of Osx on ENPP1 promoter acquired from JASPAR database. (d) Relative luciferase activities in undifferentiated MC3T3-E1 cells transfected with Osx over-expression construct, pRT-TL vector and each of the 2585-pENPP1 (1347-pENPP1, 1031-pENPP1, 829-pENPP1, 349-pENPP1, 280-pENPP1) or pGL3 basic vector (control) $\left.{ }^{* *} p<0.01\right)$. Each experiment was repeated 3 times, with technical triplicates performed. (e) ChIP results of limbs of $1 \mathrm{~d}$ postnatal mice showing the regulating sites of Osx on ENPP1 promoter $\left({ }^{* *} p<0.01\right)$. (f) ChIP results of MLO-Y4 cells showing the regulating sites of Osx on ENPP1 promoter $\left({ }^{*} p<0.05,{ }^{* *} p<0.01\right)$. All ChIP assays were repeated 3 times. 
a

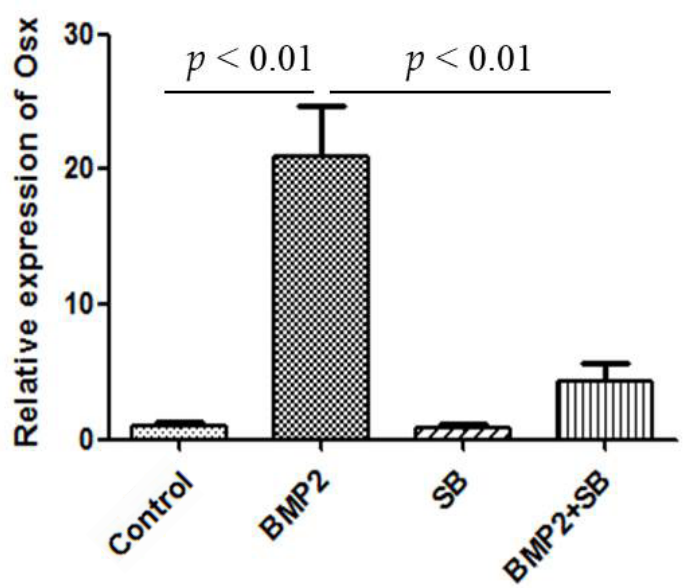

$\mathrm{c}$

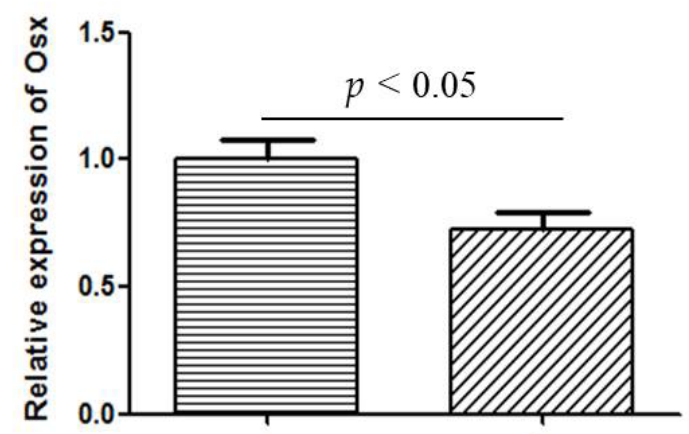

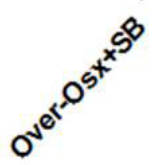

e

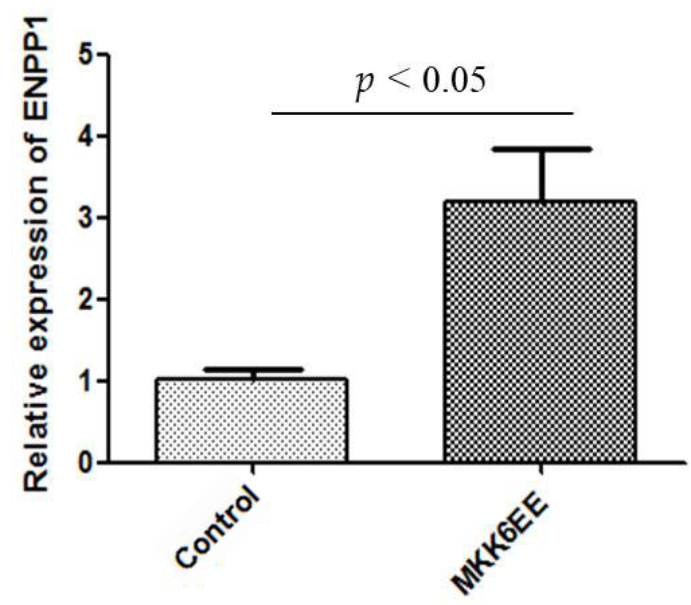

b

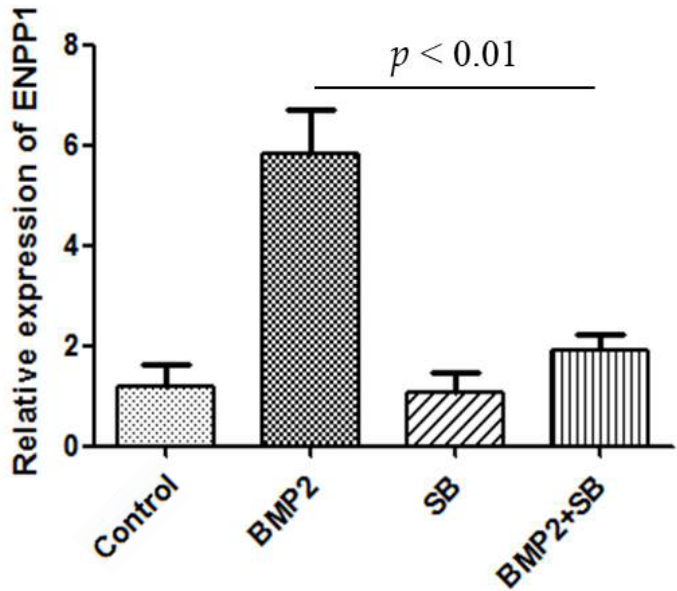

d

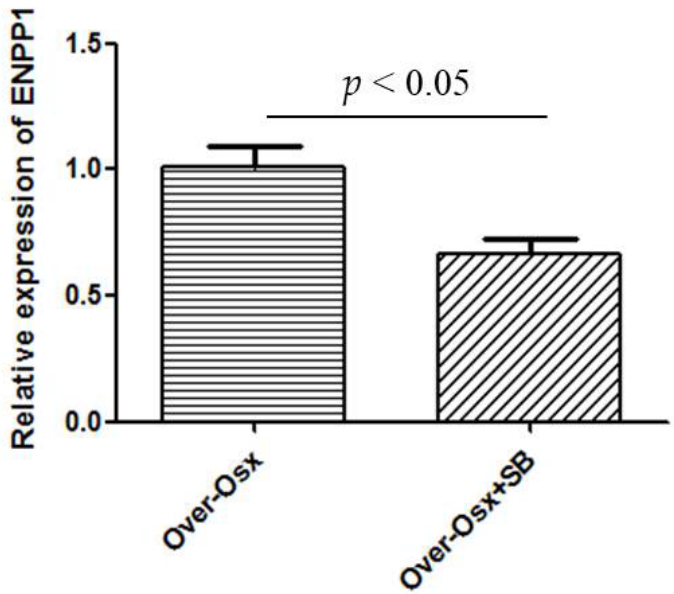

$\mathrm{f}$

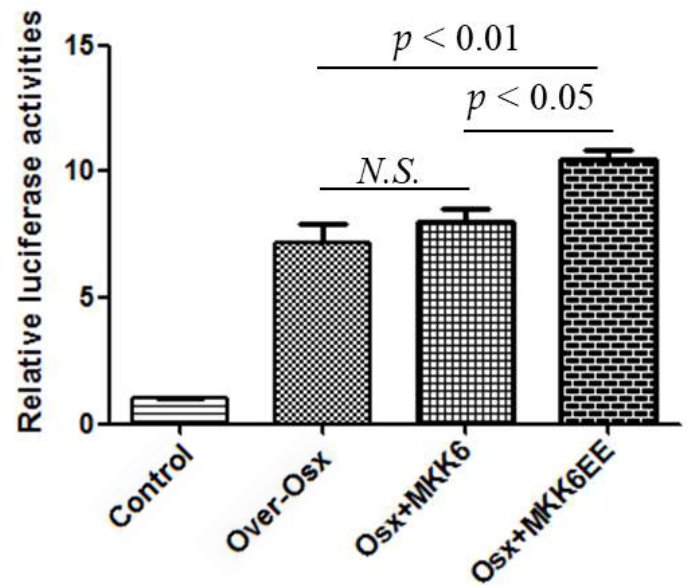

Fig. 4. Effects of p38-MAPK signalling pathway on the activation of ENPP1 promoter by Osx. Relative mRNA levels of (a) Osx and (b) ENPP1 in undifferentiated MC3T3-E1 cells treated for $24 \mathrm{~h}$ with $2 \mathrm{nM}$ BMP-2 (BMP-2), $10 \mu \mathrm{M}$ SB203580 (SB), 2 nM BMP-2 together with $10 \mu \mathrm{M}$ SB203580 (BMP-2 + SB) or basic medium (control). Relative mRNA levels of (c) Osx and (d) ENPP1 in undifferentiated MC3T3-E1 cells treated with (Over-Osx + SB) or without (Over-Osx) $10 \mu \mathrm{M}$ SB203580 in Osx over-expressing condition. (e) Relative mRNA expression of ENPP1 in undifferentiated MC3T3-E1 cells transfected with MKK6EE over-expression construct (MKK6EE) or pCDNA3.1 basic vector (control). (f) Luciferase activity in undifferentiated MC3T3-E1 cells transfected with 2585-pENPP1 construct and each of the pCDNA3.1 basic vector (control), Osx over-expression construct (over-Osx), Osx-MKK6 over-expression construct (Osx + MKK6) or Osx-MKK6EE over-expression construct (Osx + MKK6EE). All experiment were repeated 3 times, with technical triplicates performed. 
with $10 \%$ FBS for another $24 \mathrm{~h}$ to activate p38-MAPK pathway (Han et al., 1996; Raingeaud et al., 1996). RTqPCR results showed that ENPP1 was significantly increased after delivery of MKK6EE (Fig. 4e). The expression of ENPP1 was the highest with both Osx and MKK6EE over-expression (Fig. 4f).

\section{Runx2 showed synergistic transcriptional effects with Osx}

To explore the synergistic transcriptional regulation effect of Osx and Runx2 on ENPP1, the overexpression constructs were separately or cotransfected into MC3T3-E1 cells. The co-transfection group significantly increased ENPP1 expression as compared with the individual transfection groups $(p<0.05)$ (Fig. 5a). This result was confirmed by the dual-luciferase reporter assay (Fig. 5b).

\section{Discussion}

ENPP1 plays a crucial role in bone mineralisation. Previous studies have explored the regulating mechanisms of ENPP1 in pre-osteoblasts. However, its role in osteoblasts and osteocytes remains unclear. In the current study, the expression pattern of ENPP1 and Osx in vitro and in vivo was screened and the direct activation of ENPP1 promoter by Osx was demonstrated. The regulation sites were confirmed using promoter truncation experiments and ChIP assays. p38-MAPK signalling pathway was shown to contribute to the regulation process. Finally, the synergistic effects of Osx and Runx2 on the activation of ENPP1 expression were identified.

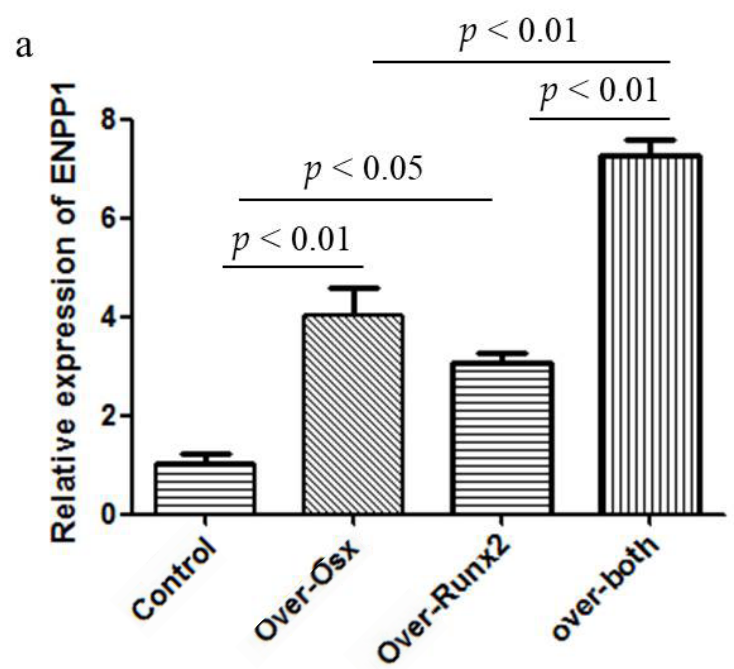

Exploring the distribution pattern of ENPP1 expression can help the understanding of its regulating mechanisms. In vitro, the expression of ENPP1 was investigated using MC3T3-E1 cells and hBMSCs during osteogenic differentiation. MC3T3-E1 is a calvaria-derived pre-osteoblast cell line that can differentiate into mature osteoblasts after $21 \mathrm{~d}$ of osteogenic cultivation (Mc et al., 2016; Ma et al., 2017). hBMSCs are widely used in osteogenesis research and can be induced into osteoblast-lineage cells and finally mature osteoblasts after $21 \mathrm{~d}$ of osteogenic cultivation (Bertram et al., 2005; Cooper et al., 2001; D' Ippolito et al., 1999). ENPP1 exhibited continuously high expression in the osteogenic conditions, similarly to Osx. The MLO-Y4 osteocyte cell line was established by Kato et al. in 1997. With very similar properties to primary osteocytes (Bonewald et al., 1999; Kato et al., 1997), MLO-Y4 cells are commonly used in osteocyte-related studies (Mattinzoli et al., 2012; Rosser and Bonewald et al., 2012; Yin et al., 2014). In the current study, ENPP1 was expressed in MLO-Y4 cells, as shown in previous studies (Kyono et al., 2012; Turner et al., 2014). In addition, a high-level of co-expression of ENPP1 with Osx was detected in MLO-Y4, as measured by confocal microscopy. These results suggested that ENPP1 was activated during the osteoblast differentiation and maturation process and in osteocytes. In vivo results showed co-distribution of ENPP1 and Osx in cortical bone and periosteum of $6 \mathrm{~d}$ postnatal mice. During development and regeneration, periosteum-derived stem cells and progenitor cells transfer or migrate to cortical bone to differentiate into osteoblasts and finally osteocytes (Ferretti and Mattioli-Belmonte et

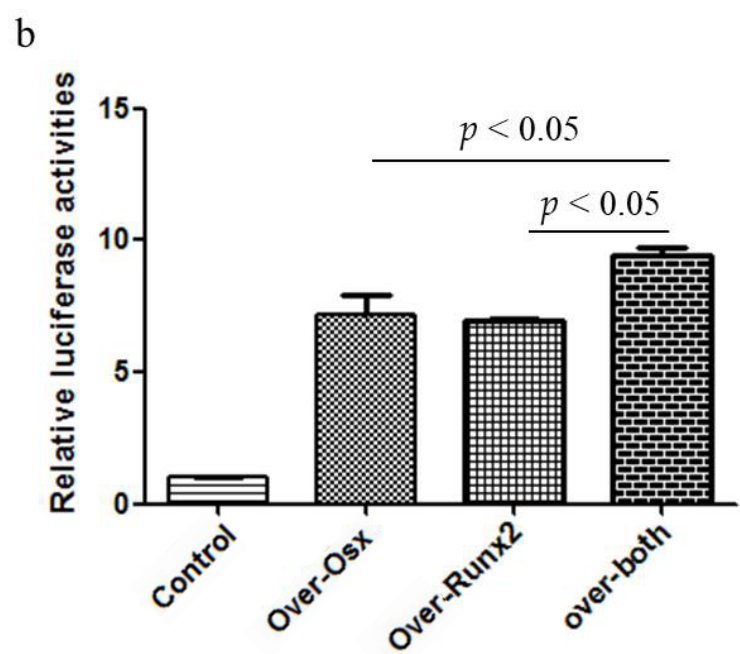

Fig. 5. Synergistic effects of Osx and Runx2 on the activation of ENPP1. (a) Relative mRNA expression of ENPP1 in undifferentiated MC3T3-E1 cells transfected with pCDNA3.1 basic vector (control), Osx over-expression construct (over-Osx), Runx2 over-expression construct (over-Runx2) or a combination of Osx over-expression construct and Runx2 over-expression construct (over-both). (b) Luciferase activity in undifferentiated MC3T3-E1 cells transfected with 2585-pENPP1 construct and each of the pCDNA3.1 basic vector, Osx over-expression construct, Runx2 over-expression construct or Osx and Runx2 overexpression constructs for $24 \mathrm{~h}$. All experiments were repeated 3 times, with technical triplicates. 
al., 2014; Hvid et al., 2016). Both in vitro and in vivo data showed similar expression pattern of ENPP1 and Osx in osteoblasts and osteocytes, suggesting the potential relationship between these two genes.

Several studies focus on the effects and mechanisms of FGF2 regulation on ENPP1 expression (Hatch et al., 2005; Hatch et al., 2009; Li et al., 2010). These studies show that FGF2 can induce Runx2 and Msx2-mediated ENPP1 expression in pre-osteoblasts. However, both Runx2 and Msx2 are down-regulated in osteoblasts and FGF2 can no longer stimulate ENPP1 expression. Although FGF2 induces ENPP1 expression in osteocytes in an extracellular-signalregulated kinase (ERK)-MAPK-dependent manner (Kyono et al., 2012), Runx2 and Msx2 hardly play regulatory roles, with little expression in osteocytes. These results imply that there are other regulating mechanisms in osteoblasts and osteocytes. As the essential transcription factor regulating osteoblast differentiation, osteocyte function and bone mineralisation homeostasis, the role of Osx in regulating ENPP1 was the focus of the current study. The current study demonstrated that ENPP1 could be directly activated by Osx in osteoblasts and osteocytes, indicating a new regulating mechanism of ENPP1 transcription. Besides ENPP1, Osx regulates several bone-mineralisation-related genes, including Col1a1 (Ortuno et al., 2013), osteocalcin (Niger et al., 2011), SATB2 (Conner and Hornick, 2013), osteopontin and sclerostin (Poole et al., 2005). It should be noted that among these genes, some promote bone mineralisation, some serve as inhibitors and some show bidirectional roles, such as ENPP1. Therefore, Osx acts as a coordinator to guide normal bone mineralisation. Either dysfunction or over-expression of Osx could lead to abnormal bone mineralisation (Zhou, et al., 2010).

p38-MAPK is one of the most critical pathways regulating osteogenic differentiation and mineralisation (Greenblatt et al., 2010; Hu et al., 2003). During osteogenesis, p38 is crucial for activating Osx (Ortuno et al., 2010; Wang et al., 2007) and it is involved in the transcription regulation of Osx on target genes (Ortuno et al., 2013). The results of the current study demonstrated that p38 contributed to the activation of ENPP1 by Osx. Interestingly, $\mathrm{PPi}$, the primary product of ENPP1, can in turn induce p38-MAPK pathway to increase osteopontin expression, which restrains the mineralisation process (Ortuno et al., 2010). In addition to p38, ERK1/2 is another important kinase that regulates Osx (Choi et al., 2011). However, previous studies show variable results regarding ERK1/2 regulation of Osx, as well as ENPP1, in different conditions. Xiao et al. (2013) report that in MSCs, activation of ERK-MAPK signalling pathway inhibits Osx expression, leading to impaired osteogenesis and abnormal mineralisation. On the contrary, Byun et al. (2014) show that activating ERK-MAPK pathway can stimulate MSCs osteogenic differentiation by activating Osx. Similarly to the debated effect on Osx,
ERK1/2 regulation of ENPP1 expression is also not clearly definite. In osteocytes, FGF2 can up-regulate ENPP1 in an ERK-MAPK-dependent manner (Kyono et al., 2012), whereas FGF2 has no effect on ENPP1 expression in osteoblasts, suggesting that the effects of ERK1/2 on ENPP1 expression are different from osteoblasts to osteocytes. However, the results of the present study showed that Osx regulated ENPP1 expression in both osteoblasts and osteocytes, suggesting that ERK1/2 may not be a key player in contributing to Osx activation of ENPP1 expression.

In the promoter truncation experiments, the luciferase activity decreased after truncation of the two proximal binding sites, indicating that the secondary proximal binding site might have the highest activity. The luciferase activity was still much higher than the control group after truncation of all the 5 predicted binding sites, suggesting that Osx could activate ENPP1 expression by binding to the left sequence, most of which belonged to 5 ' UTR. The 5' UTR functions as a regulatory element in some genes (Bonnet-Magnaval et al., 2016; Drissi et al., 2000; Guo and Lu et al., 2017). More work should be carried out to identify the regulatory elements in the 5' UTR of ENPP1.

The ChIP assays, using bone specimens of $6 \mathrm{~d}$ postnatal mice, confirmed that Osx could bind any of the 5 predicted binding sites, which confirmed the promoter truncation experiments. The specific function of each binding site, as well as the interaction between them, should be further investigated. In the present study, mice tibiae were utilised for ChIP assays to reflect the in vivo situation. However, the effective input of each binding site should be calculated as the average of the different cell types utilised. In MLO-Y4 osteocyte cell line, results of ChIP assays showed that Osx could not bind the site 4 (- $349 \sim-340)$ of ENPP1 promoter, suggesting a cell-specific regulating mechanisms. To identify the regulating mechanisms in the specific cell stage, more detailed studies should be carried out in the future.

Osx has synergistic roles with Runx2 in the activation of several target genes, such as Col1a1 (Artigas, et al., 2014; Ortuno, et al., 2013), Fmod and Ibsp (Artigas, et al., 2014). Runx2 activates ENPP1 promoter in pre-osteoblasts and the proximal binding sites are close to Osx binding sites (Hatch, Li and Franceschi, 2009). For these reasons, the synergistic roles of these two transcription factors in activating ENPP1 promoter were explored. The results showed that Osx and Runx 2 had additive effects on ENPP1 promoter activation. Moreover, although ENPP1 was regulated by different mechanisms at various stages of differentiation, the two key factors were closely correlated with each other.

\section{Conclusion}

Osx, a key transcriptional factor in osteoblasts and osteocytes, significantly activated ENPP1 
transcription. Different conditions affected Osx binding to its 5 binding sites on the ENPP1 promoter. The p38-MAPK pathway contributed to this regulatory process. In addition, Runx2 showed synergistic roles with Osx in activating ENPP1 expression. This was the first description of the regulating mechanisms of ENPP1 expression in osteoblasts and osteocytes.

\section{Acknowledgement}

The present study was financially supported by the National Natural Science Foundation of China (No. 31430030, 81772400), Natural Science Foundation of Guangdong Province (2017A030308004, 2014A030310466) and Natural Science Foundation of Guangzhou City (2018-1003-SF-0172, 201604046028 and 201807010031). Zhiyu Zhou and Manman Gao were funded by the China Scholarship Council.

\section{References}

Addison WN, Azari F, Sorensen ES, Kaartinen MT, McKee MD (2007) Pyrophosphate inhibits mineralization of osteoblast cultures by binding to mineral, up-regulating osteopontin, and inhibiting alkaline phosphatase activity. J Biol Chem 282: 1587215883.

Artigas N, Urena C, Rodriguez-Carballo E, Rosa JL, Ventura F (2014) Mitogen-activated protein kinase (MAPK)-regulated interactions between Osterix and Runx2 are critical for the transcriptional osteogenic program. J Biol Chem 289: 27105-27117.

Bertram H, Mayer H, Schliephake H (2005) Effect of donor characteristics, technique of harvesting and in vitro processing on culturing of human marrow stroma cells for tissue engineered growth of bone. Clin Oral Implants Res 16: 524-531.

Bodnar AG, Ouellette M, Frolkis M, Holt SE, Chiu CP, Morin GB, Harley CB, Shay JW, Lichtsteiner S, Wright WE (1998) Extension of life-span by introduction of telomerase into normal human cells. Science 279: 349-352.

Bonewald LF. Establishment and characterization of an osteocyte-like cell line, MLO-Y4 (1999) J Bone Miner Metab 17: 61-65.

Bonnet-Magnaval F, Philippe C, Van Den Berghe L, Prats H, Touriol C, Lacazette E (2016) Hypoxia and ER stress promote Staufen1 expression through an alternative translation mechanism. Biochem Biophys Res Commun 479: 365-371.

Byun MR, Kim AR, Hwang JH, Kim KM, Hwang ES, Hong JH (2014) FGF2 stimulates osteogenic differentiation through ERK induced TAZ expression. Bone 58: 72-80.

Choi YH, Gu YM, Oh JW, Lee KY (2011) Osterix is regulated by Erk1/2 during osteoblast differentiation. Biochem Biophys Res Commun 415: 472-478.
Conner JR, Hornick JL (2013) SATB2 is a novel marker of osteoblastic differentiation in bone and soft tissue tumours. Histopathology 63: 36-49.

Cooper LF, Harris CT, Bruder SP, Kowalski R, Kadiyala S (2001) Incipient analysis of mesenchymal stem-cell-derived osteogenesis. J Dent Res 80: 314320.

D' Ippolito G, Schiller PC, Ricordi C, Roos BA, Howard GA (1999) Age-related osteogenic potential of mesenchymal stromal stem cells from human vertebral bone marrow. J Bone Miner Res 14: 11151122.

Drissi H, Luc Q, Shakoori R, Chuva DSLS, Choi JY, Terry A, Hu M, Jones S, Neil JC, Lian JB, Stein JL, Van Wijnen AJ, Stein GS (2000) Transcriptional autoregulation of the bone related CBFA1/Runx2 gene. J Cell Physiol 184: 341-350.

Evans WH, Hood DO, Gurd JW (1973) Purification and properties of a mouse liver plasma-membrane glycoprotein hydrolysing nucleotide pyrophosphate and phosphodiester bonds. Biochem J 135: 819-826.

Ferretti C, Mattioli-Belmonte M (2014) Periosteum derived stem cells for regenerative medicine proposals: boosting current knowledge. World J Stem Cells 6: 266-277.

Greenblatt MB, Shim JH, Zou W, Sitara D, Schweitzer M, Hu D, Lotinun S, Sano Y, Baron R, Park JM, Arthur S, Xie M, Schneider MD, Zhai B, Gygi S, Davis R, Glimcher LH (2010) The p38 MAPK pathway is essential for skeletogenesis and bone homeostasis in mice. J Clin Invest 120: 2457-2473.

Guo S, Lu H (2017) Conjunction of potential G-quadruplex and adjacent cis-elements in the 5' UTR of hepatocyte nuclear factor 4-alpha strongly inhibit protein expression. Sci Rep 7: DOI: 10.1038/ s41598-017-17629-y.

Han J, Lee JD, Jiang Y, Li Z, Feng L, Ulevitch RJ (1996) Characterization of the structure and function of a novel MAP kinase kinase (MKK6). J Biol Chem 271: 2886-2891.

Hatch NE, Li Y, Franceschi RT (2009) FGF2 stimulation of the pyrophosphate-generating enzyme, PC-1, in pre-osteoblast cells is mediated by Runx2. J Bone Miner Res 24: 652-662.

Hatch NE, Nociti F, Swanson E, Bothwell M, Somerman M (2005) FGF2 alters expression of the pyrophosphate/phosphate regulating proteins, PC-1, ANK and TNAP, in the calvarial osteoblastic cell line, MC3T3E1(C4). Connect Tissue Res 46: 184-192.

Hessle L, Johnson KA, Anderson HC, Narisawa S, Sali A, Goding JW, Terkeltaub R, Millan JL (2002) Tissue-nonspecific alkaline phosphatase and plasma cell membrane glycoprotein- 1 are central antagonistic regulators of bone mineralization. Proc Natl Acad Sci U S A 99: 9445-9449.

Hu Y, Chan E, Wang SX, Li B (2003) Activation of p38 mitogen-activated protein kinase is required for osteoblast differentiation. Endocrinology 144: 20682074.

Hvid I, Horn J, Huhnstock S, Steen H. The biology of bone lengthening (2016) J Child Orthop 10: 487-492. 
Isaac J, Erthal J, Gordon J, Duverger O, Sun HW, Lichtler AC, Stein GS, Lian JB, Morasso MI (2014) DLX3 regulates bone mass by targeting genes supporting osteoblast differentiation and mineral homeostasis in vivo. Cell Death Differ 21: 1365-1376.

Kato K, Nishimasu H, Okudaira S, Mihara E, Ishitani R, Takagi J, Aoki J, Nureki O (2012) Crystal structure of Enpp1, an extracellular glycoprotein involved in bone mineralization and insulin signaling. Proc Natl Acad Sci U S A 109: 16876-16881.

Kato Y, Windle JJ, Koop BA, Mundy GR, Bonewald LF (1997) Establishment of an osteocyte-like cell line, MLO-Y4. J Bone Miner Res 12: 2014-2023.

Kyono A, Avishai N, Ouyang Z, Landreth GE, Murakami S (2012) FGF and ERK signaling coordinately regulate mineralization-related genes and play essential roles in osteocyte differentiation. J Bone Miner Metab 30: 19-30.

Li Y, Liu J, Hudson M, Kim S, Hatch NE (2010) FGF2 promotes Msx2 stimulated PC-1 expression via Frs2/MAPK signaling. J Cell Biochem 111: 1346-1358.

Ma J, Guo W, Gao M, Huang B, Qi Q, Ling Z, Chen Y, Hu H, Zhou H, Yu F, Chen K, Richards G, Lin J, Zhou Z, Xiao D, Zou X (2017) Biomimetic matrix fabricated by LMP-1 gene-transduced MC3T3-E1 cells for bone regeneration. Biofabrication 9: DOI: 10.1088/1758-5090/aa8dd1.

Mackenzie NC, Zhu D, Milne EM, van T HR, Martin A, Darryl QL, Millan JL, Farquharson C, MacRae VE (2012) Altered bone development and an increase in FGF-23 expression in Enpp1(-/-) mice. PLoS One 7: DOI: 10.1371/journal.pone.0032177.

Mattinzoli D, Messa P, Corbelli A, Ikehata M, Zennaro C, Armelloni S, Li M, Giardino L, Rastaldi MP (2012) A novel model of in vitro osteocytogenesis induced by retinoic acid treatment. Eur Cell Mater 24: 403-425.

Mc GM, Mullen CA, Haugh MG, Voisin MC, McNamara LM (2016) Osteocyte differentiation and the formation of an interconnected cellular network in vitro. Eur Cell Mater 31: 323-340.

Moss DW, Eaton RH, Smith JK, Whitby LG (1967) Association of inorganic-pyrophosphatase activity with human alkaline-phosphatase preparations. Biochem J 102: 53-57.

Nakashima K, Zhou X, Kunkel G, Zhang Z, Deng JM, Behringer RR, de Crombrugghe B (2002) The novel zinc finger-containing transcription factor osterix is required for osteoblast differentiation and bone formation. Cell 108: 17-29.

Nam HK, Liu J, Li Y, Kragor A, Hatch NE (2011) Ectonucleotide pyrophosphatase/ phosphodiesterase-1 (ENPP1) protein regulates osteoblast differentiation. J Biol Chem 286: 3905939071.

Nam HK, Sharma M, Liu J, Hatch NE (2017) Tissue nonspecific alkaline phosphatase (TNAP) regulates cranial base growth and synchondrosis maturation. Front Physiol 8: DOI: 10.3389/fphys.2017.00161.
Niger C, Lima F, Yoo DJ, Gupta RR, Buo AM, Hebert C, Stains JP (2011) The transcriptional activity of osterix requires the recruitment of Sp1 to the osteocalcin proximal promoter. Bone 49: 683-692.

Okawa A, Nakamura I, Goto S, Moriya H, Nakamura Y, Ikegawa S (1998) Mutation in Npps in a mouse model of ossification of the posterior longitudinal ligament of the spine. Nat Genet 19: 271-273.

Ortuno MJ, Ruiz-Gaspa S, Rodriguez-Carballo E, Susperregui AR, Bartrons R, Rosa JL, Ventura F (2010) p38 regulates expression of osteoblast-specific genes by phosphorylation of osterix. J Biol Chem 285: 31985-31994.

Ortuno MJ, Susperregui AR, Artigas N, Rosa JL, Ventura F (2013) Osterix induces Colla1 gene expression through binding to Sp1 sites in the bone enhancer and proximal promoter regions. Bone 52: 548-556.

Perez-Campo FM, Santurtun A, Garcia-Ibarbia C, Pascual MA, Valero C, Garces C, Sanudo C, Zarrabeitia MT, Riancho JA (2016) Osterix and Runx2 are transcriptional regulators of sclerostin in human bone. Calcif Tissue Int 99: 302-309.

Poole KE, van Bezooijen RL, Loveridge N, Hamersma H, Papapoulos SE, Lowik CW, Reeve J (2005) Sclerostin is a delayed secreted product of osteocytes that inhibits bone formation. FASEB J 19: 1842-1844.

Raingeaud J, Whitmarsh AJ, Barrett T, Derijard B, Davis RJ (1996) MKK3- and MKK6-regulated gene expression is mediated by the p38 mitogen-activated protein kinase signal transduction pathway. Mol Cell Biol 16: 1247-1255.

Rosser J, Bonewald LF (2012) Studying osteocyte function using the cell lines MLO-Y4 and MLO-A5. Methods Mol Biol 816: 67-81.

Rutsch F, Ruf N, Vaingankar S, Toliat MR, Suk A, Hohne W, Schauer G, Lehmann M, Roscioli T, Schnabel D, Epplen JT, Knisely A, Superti-Furga A, McGill J, Filippone M, Sinaiko AR, Vallance H, Hinrichs B, Smith W, Ferre M, Terkeltaub R, Nurnberg P (2003) Mutations in ENPP1 are associated with 'idiopathic' infantile arterial calcification. Nat Genet 34: 379-381.

Sakamoto M, Hosoda Y, Kojimahara K, Yamazaki T, Yoshimura Y (1994) Arthritis and ankylosis in twy mice with hereditary multiple osteochondral lesions: with special reference to calcium deposition. Pathol Int 44: 420-427.

Stefan C, Jansen S, Bollen M (2005) NPP-type ectophosphodiesterases: unity in diversity. Trends Biochem Sci 30: 542-550.

Tang Y, Huang B, Sun L, Peng X, Chen X, Zou $X$ (2011) Ginkgolide B promotes proliferation and functional activities of bone marrow-derived endothelial progenitor cells: involvement of Akt/ eNOS and MAPK/p38 signaling pathways. Eur Cell Mater 21: 459-469. 
Turner AG, Hanrath MA, Morris HA, Atkins GJ, Anderson PH (2014) The local production of $1,25(\mathrm{OH}) 2 \mathrm{D} 3$ promotes osteoblast and osteocyte maturation. J Steroid Biochem Mol Biol 144 Pt A: 114-118.

Wang X, Goh CH, Li B (2007) p38 mitogenactivated protein kinase regulates osteoblast differentiation through osterix. Endocrinology 148: 1629-1637.

Wolbank S, Stadler G, Peterbauer A, Gillich A, Karbiener M, Streubel B, Wieser M, Katinger H, van Griensven M, Redl H, Gabriel C, Grillari J, Grillari-Voglauer R (2009) Telomerase immortalized human amnion- and adipose-derived mesenchymal stem cells: maintenance of differentiation and immunomodulatory characteristics. Tissue Eng Part A 15: 1843-1854.

Xiao L, Esliger A, Hurley MM (2013) Nuclear fibroblast growth factor 2 (FGF2) isoforms inhibit bone marrow stromal cell mineralization through FGF23/FGFR/MAPK in vitro. J Bone Miner Res 28: 35-45.

Yin J, Hao Z, Ma Y, Liao S, Li X, Fu J, Wu Y, Shen J, Zhang P, Li X, Wang H (2014) Concomitant activation of the PI3K/Akt and ERK1/2 signalling is involved in cyclic compressive force-induced IL-6 secretion in MLO-Y4 cells. Cell Biol Int 38: 591-598.

Yoshida CA, Komori H, Maruyama Z, Miyazaki T, Kawasaki K, Furuichi T, Fukuyama R, Mori M, Yamana K, Nakamura K, Liu W, Toyosawa S, Moriishi T, Kawaguchi H, Takada K, Komori T (2012) SP7 inhibits osteoblast differentiation at a late stage in mice. PLoS One 7: DOI: 10.1371/journal.pone.0032364.

Zhou X, Zhang Z, Feng JQ, Dusevich VM, Sinha K, Zhang H, Darnay BG, de Crombrugghe B (2010) Multiple functions of Osterix are required for bone growth and homeostasis in postnatal mice. Proc Natl Acad Sci U S A 107: 12919-12924.

\section{Web References}

1. http://genome.ucsc.edu/cgi-bin/hgGateway [14-06-2018]

2. http://genome.ucsc.edu/cgi-bin/hgBlat [14-062018]

3. http://www.cbs.dtu.dk/services/Promoter/ [1406-2018]

4. http://jaspar.genereg.net/ [14-06-2018]

\section{Discussion with reviewers}

Chang Du: It seems that specific-age mice were chosen for the study. What was the rational and what about using mice of different ages?

Authors: The primary ossification centre and the growth plate appear at E14.5 in C57BL6 mice (Tomlinson et al., 2016; Zhu et al., 2009; additional references). 1 to $7 \mathrm{~d}$ postnatal mice show a rapidly growing growth plate, which has each layer easily distinguished in the histological evaluations. Thus, $1 \mathrm{~d}$ postnatal mice were convenient for ChIP experiments, while $6 \mathrm{~d}$ postnatal mice were better suited for immunofluorescence, helping to differentiate the layers of the growth plate.

Chang Du: Why did the author choose a $3 \mathrm{kbp}$-long promoter sequence in the Dual-Luciferase ${ }^{\circledR}$ reporter assays? Might a region longer than $3 \mathrm{kbp}$ have some effects?

Authors: Transcription factors binding sites are usually located within $2 \mathrm{kbp}$ upstream of exon 1 (Chan et al., 2006; Ognjanovic, et al., 2001; additional references). In previous studies on ENPP1 transcriptional regulation, a $3 \mathrm{kbp}$-long region upstream of exon 1 is used (Bouchareb, et al., 1995; Hatch, et al., 2007; Li et al., 2010; additional references). For this reason, a $3 \mathrm{kbp}$-long promoter sequence was used in the current study. In some cases, transcription factor binding sites are locate more than $3 \mathrm{kbp}$ upstream of exon 1 (Hindorff et al., 2009; Korhonen, et al., 1995; Zhao, et al., 2007; additional references). However, there is no such evidence for ENPP1 gene transcriptional regulation.

\section{Additional references}

Bouchareb R, Boulanger MC, Fournier D, Pibarot P, Messaddeq Y, Mathieu P (2014) Mechanical strain induces the production of spheroid mineralized microparticles in the aortic valve through a RhoA/ ROCK-dependent mechanism. J Mol Cell Cardiol 67: 49-59.

Chan TL, Yuen ST, Kong CK, Chan YW, Chan AS, Ng WF, Tsui WY, Lo MW, Tam WY, Li VS, Leung SY (2006) Heritable germline epimutation of MSH2 in a family with hereditary nonpolyposis colorectal cancer. Nat Genet 38: 1178-1183.

Hatch NE, Y Li, Franceschi RT (2009) FGF2 stimulation of the pyrophosphate-generating enzyme, PC-1, in pre-osteoblast cells is mediated by Runx2. J Bone Miner Res 24: 652-662.

Hindorff LA, Sethupathy P, Junkins HA, Ramos EM, Mehta JP, Collins FS, Manolio TA (2009) Potential etiologic and functional implications of genome-wide association loci for human diseases and traits. Proc Natl Acad Sci U S A 106: 9362-9367.

Korhonen J, Lahtinen I, Halmekytö M, Alhonen L, Jänne J, Dumont D, Alitalo K (1995) Endothelialspecific gene expression directed by the tie gene promoter in vivo. Blood 86: 1828-1835.

Li Y, Liu J, Hudson M, Kim S, Hatch NE (2010) FGF2 promotes Msx2 stimulated PC-1 expression via Frs2/MAPK signaling. J Cell Biochem 111: 1346-1358.

Ognjanovic S, Bao S, Yamamoto SY, GaribayTupas J, Samal B, Bryant-Greenwood GD (2001) Genomic organization of the gene coding for human pre-B-cell colony enhancing factor and expression in human fetal membranes. J Mol Endocrinol 26: 107117. 
Tomlinson RE, Li Z, Zhang Q, Goh BC, Li Z, Thorek DLJ, Rajbhandari L, Brushart TM, Minichiello L, Zhou F, Venkatesan A, Clemens TL (2016) NGFTrkA signaling by sensory nerves coordinates the vascularization and ossification of developing endochondral bone. Cell Rep 16: 2723-2735.

Zhao J, Brault JJ, Schild A, Cao P, Sandri M, Schiaffino S, Lecker SH, Goldberg AL (2007) FoxO3 coordinately activates protein degradation by the autophagic/lysosomal and proteasomal pathways in atrophying muscle cells. Cell Metab 6: 472-483.

Zhu XB, Zhou JS, Xiao YZ, Deng LF (2009) [Expression of hypoxia inducible factor-1alpha in long bone development]. Zhongguo Gu Shang 22: 599-601.

Editor's note: The Scientific Editor responsible for this paper was Chris Evans. 